\title{
Joint Goals in Older Couples: Associations With Goal Progress, Allostatic Load, and Relationship Satisfaction
}

\author{
Nadine Ungar ${ }^{1}$, Victoria I. Michalowski ${ }^{1}$, Stella Baehring ${ }^{1}$, Theresa Pauly ${ }^{1}$, \\ Denis Gerstorf ${ }^{2}$, Maureen C. Ashe ${ }^{3,4}$, Kenneth M. Madden ${ }^{3,5}$ and \\ Christiane A. Hoppmann ${ }^{1,3 *}$
}

${ }^{1}$ Department of Psychology, University of British Columbia, Vancouver, BC, Canada, ${ }^{2}$ Department of Psychology, Humboldt University Berlin, Berlin, Germany, ${ }^{3}$ Center for Hip Health and Mobility, Vancouver, BC, Canada, ${ }^{4}$ Department of Family Practice, University of British Columbia, Vancouver, BC, Canada, ${ }^{5}$ Department of Medicine, University of British Columbia, Vancouver, BC, Canada

\section{OPEN ACCESS}

Edited by:

Anne Milek,

University of Münster, Germany

Reviewed by:

Joan Monin,

Yale University, United States

Ariela Francesca Pagani,

Catholic University of the Sacred

Heart, Italy

${ }^{*}$ Correspondence:

Christiane A. Hoppmann

choppmann@psych.ubc.ca

Specialty section:

This article was submitted to Personality and Social Psychology, a section of the journal

Frontiers in Psychology

Received: 29 October 2020 Accepted: 08 March 2021

Published: 20 April 2021

Citation:

Ungar N, Michalowski VI, Baehring S,

Pauly T, Gerstorf D, Ashe MC, Madden KM and Hoppmann CA (2021) Joint Goals in Older Couples: Associations With Goal Progress, Allostatic Load, and Relationship Satisfaction.

Front. Psychol. 12:623037. doi: 10.3389/fpsyg.2021.623037
Older adults often have long-term relationships, and many of their goals are intertwined with their respective partners. Joint goals can help or hinder goal progress. Little is known about how accurately older adults assess if a goal is joint, the role of over-reporting in these perceptions, and how joint goals and over-reporting may relate to older partners' relationship satisfaction and physical health (operationally defined as allostatic load). Two-hundred-thirty-six older adults from 118 couples (50\% female; $M_{\text {age }}=71$ years) listed their three most important goals and whether they thought of them as goals they had in common with and wanted to achieve together with their partner (self-reported joint goals). Two independent raters classified goals as "joint" if both partners independently listed open-ended goals of the same content. Goal progress and relationship satisfaction were assessed 1 week later. Allostatic load was calculated using nine different biomarkers. Results show that $85 \%$ self-reported at least one goal as joint. Over-reporting - the perception that a goal was joint when in fact it was not mentioned among the three most salient goals of the spouse - occurred in one-third of all goals. Multilevel models indicate that the number of externally-rated joint goals was related to greater goal progress and lower allostatic load, but only for adults with little over-reporting. More joint goals and higher over-reporting were each linked with more relationship satisfaction. In conclusion, joint goals are associated with goal progress, relationship satisfaction, and health, but the association is dependent on the domain of functioning.

Keywords: close relationships, joint goals, older adults, relationship satisfaction, allostatic load, goal progress, couple, health

\section{INTRODUCTION}

Many marriages in old age are long-term relationships (Meegan and Berg, 2002). Older spouses tend to become more central to each other due to an increased focus on close, emotionally meaningful relationships (Baltes and Carstensen, 1999). Partners shape each other's behavior, physiology, and health (e.g., review by Kiecolt-Glaser and Wilson, 2017). One underlying mechanism may be shared goals (Lauer et al., 1990; Berg and Upchurch, 2007). Goals serve as a personal compass into old age (Hooker, 2002). Goals are mostly examined in samples of 
unrelated individuals, and yet, they often need to be coordinated with close others such as spouses (Baltes and Carstensen, 1999; Mann et al., 2013; Fitzsimons and Finkel, 2018). Little is known about the proportion and type of goals that older spouses have in common and the correlates for everyone involved. Using a sample of 118 older couples, this brief report seeks to fill this gap by investigating the joint nature of everyday goals, taking into account the perspective of both partners as well as potential implications for goal progress, health, and relationship satisfaction.

\section{Joint Goals and Goal Progress}

We operationally define goals as joint when spouses report goals they have in common and want to achieve together with their partner. Extending research with younger couples and a focus on relationship goals (Avivi et al., 2009) we assume that a higher number of joint goals allows older spouses to pool their resources and make better goal progress.

Importantly, partner ratings of a goal as joint might not always be accurate; instead, they may be positively biased (Martz et al., 1998; Gagné and Lydon, 2004). Known as the "positivity effect," older adults prioritize positive over negative information (Baltes and Carstensen, 1999; Carstensen et al., 2003). Older adults also view their spouse's behavior as more positive during conflict than middle-aged couples in the eye of independent observers (Story et al., 2007). We, therefore, assume that perceptions of goals as joint may not always be accurate but positively biased in the present sample. In other words, older spouses may over-report joint goals relative to external raters. Over-reporting occurs if older adults - thinking of joint goals as joint when in fact it is no mentioned among the three most salient goals of the spouse. In line with the Transactive-Goal-Dynamics Theory (Fitzsimons and Finkel, 2018) and previous research indicating that older couples with more joint goals use more collaborative problemsolving (Hoppmann and Gerstorf, 2013) and engage in more spousal goal involvement (Meegan and Goedereis, 2006), we argue that to translate joint goals into action, goal coordination between partners is key. To collaboratively engage in goal coordination, the Transactive-Goal-Dynamics Theory states that it is necessary that partners adjust their behavior to each other's goal-relevant states (e.g., expectations). A discrepancy between assumed and actual joint goals makes that difficult and may thus hinder goal coordination and ultimately goal progress. We thus assume that joint goals can be better pursued if both partners have correct insights into each other's salient goals, which facilitates goal coordination. Therefore, we expect that more joint goals are associated with greater goal progress, particularly when older adults accurately perceive their salient goals as jointly held, i.e., they engage in little over-reporting.

\section{Joint Goals and Allostatic Load}

Joint goals may not only impact everyday behaviors but also shape health outcomes, possibly through stress-related pathways and lifestyle factors (Hoppmann and Klumb, 2006; Hoppmann and Gerstorf, 2014; Feeney and Collins, 2015). This may be particularly true among older adults due to age-related wear and tear (Seeman and Gruenewald, 2006). A well-established index of stress-related wear-and-tear is allostatic load (Seeman et al., 2004). Allostatic load taps into different biological systems, including neuroendocrine and cardiovascular risk markers (Seeman and Gruenewald, 2006). Previous research indicates that social factors such as positive and close relationships, spousal presence and social support are linked to reduced allostatic load (Seeman et al., 2002; Juster et al., 2010; Brooks et al., 2014; Priest et al., 2015). In contrast, higher spouse and family negativity are related to higher allostatic load (Brooks et al., 2014). We expected that a high number of joint goals would be associated with low allostatic load, possibly because older spouses with many joint goals are better able to coordinate complex health goals, engage in dyadic planning, and accordingly have healthier lifestyles and experience less stress (Keller et al., 2017; Wiley et al., 2017; Berli et al., 2018; Fitzsimons and Finkel, 2018). Thus, we expect that when older adults' perceptions of joint goals converge with what independent raters are able to detect, they can better coordinate goal-directed activity. Therefore, parallel to our hypothesis regarding goal progress, we expect the association between joint goals and low allostatic load to be more pronounced if older adults accurately perceive their goals as jointly held, i.e., they engage in little over-reporting.

\section{Joint Goals and Relationship Satisfaction}

With increasing age and a limited future time perspective, there is a shift in goals toward emotionally meaningful social relationships (English and Carstensen, 2014). Therefore, we aimed to investigate - as a third relevant correlate - how joint goals might be related to relationship satisfaction. The Eudaimonic Theory of Marital Quality proposes that shared goals are central ingredients of marital satisfaction (Fowers and Owenz, 2010). Shared goals address inherent needs for security and belonging and foster dyadic processes such as the inclusion of the partner in the self, couple identity, and commitment. We assume that rosy-colored views of goals as shared with a partner would be positively associated with relationship satisfaction and that this association would not be tempered by positively biased over-reporting of joint goals as relationship satisfaction may be based on subjective perceptions and is less behavioral than the other two indicators. Accordingly, we expected that more joint goals would be associated with higher relationship satisfaction.

\section{The Current Study}

Incorporating the perspective of both spouses, this brief report elucidates how joint goals are linked with goal progress, health, and relationship satisfaction taking into account meaningful differences between subjective and external ratings of joint goals. Specifically, we hypothesized that more joint goals would be related to greater goal progress (hypothesis 1, Hp1), lower allostatic load (Hp2), and higher relationship satisfaction ( $\mathrm{Hp} 3)$. In line with motivational theories, we assumed that goal coordination is necessary to translate joint goals into goal progress and allostatic load. Thus, we expected the associations between joint goals and goal progress and allostatic load to be stronger if older adults accurately perceived their salient goals as jointly held (moderation effect). 


\section{METHODS}

\section{Participants}

Participants were 118 community-dwelling couples $(N$ $=236$ individuals). From the original 258 participants who entered the study, nine couples dropped out after the baseline session and two further couples had to be excluded due to missing values on the main outcome variables. The sample included ethnically diverse heterosexual couples aged 60-87 years $(M=$ 71.01, $S D=5.97)$ as described in Table 1. $82.4 \%$ of couples were married and $7.6 \%$ lived in a domestic partnership; relationship duration was 41.01 years on average $(S D=13.30)$.

\section{Procedure}

The study was part of a larger project on spousal health dynamics (described in Supplementary Material 1 and Pauly et al., 2019). Couples were recruited in the greater Vancouver area using various strategies (e.g., media, community organizations). Informed consent was obtained (University of British Columbia ethics board), and each partner received $\$ 100$ compensation. The study consisted of a baseline-session, a 1-week time-sampling phase, and an exit-session 1 week later.

\section{Measures}

\section{Personal Goals and Self-Reported Joint Goals}

Participants reported three open-ended, particularly salient goals $(A, B, C)$ whose realization was highly important to them within the upcoming week (based on Hoppmann and Klumb, 2006; see Supplementary Material 2). Afterward, participants self-rated their goals along 12 domains (e.g., "work," "family," multiple answers possible). For each goal, participants were asked, "Is this a goal that you and your partner have in common and want to achieve together?." This measure was used to calculate the self-reported number of joint goals (range 0-3) with a mean of $M=1.77, S D=1.05$.

\section{Externally-Rated Joint Goals}

Participants' three salient goals were also rated by two independent raters (NU and SB). They classified the goals as joint (=both partners mentioning the same goal) or individual (=goal was only mentioned by one partner) using a prior developed coding scheme (see Supplementary Material 3). For example, a goal was rated as joint if both partners mentioned the same activity, the same place, or the same third person. A goal was additionally rated as joint if one goal represented a subcategory of the other (e.g., "cleaning the house" and "cleaning the kitchen"). It was rated as individual if goals involved distinct activities (e.g., "swimming" vs. "tennis").

Agreement between the independent raters was high (645 of 708 goals; $91.10 \%)$. In case of disagreement, a consensus was achieved during a discussion. Interrater-reliability was substantial (Cohen's Kappa = 0.794). The calculation of Cohen's Kappa is conservative in our case because it does not account for the order of potential goal combinations.

\section{Over-Reporting of Joint Goals}

To calculate over-reporting, externally-rated joint goals were compared to self-reported joint goals. If participants reported that they wanted to achieve a goal together with their partner, but the partner did not mention this goal, it was classified as "over-reported." All other combinations counted as "not overreported"1. For each participant, over-reporting was added up across all three goals. Thus, "over-reporting" ranged from 0 to 3 with a mean of $M=1.04, S D=0.92$.

\section{Goal Progress Questionnaire}

At the exit session, participants rated their goal progress since the baseline session, i.e., over the last week. For each goal separately, participants rated (1) their goal progress and (2) the extent to which they had reached that goal $(1=$ none to $5=$ a lot; $M=$ $3.11, S D=0.93)$.

\section{Allostatic Load}

Allostatic Load was calculated as a sum score taking four different physiological systems into account (Seeman and Gruenewald, 2006; Chen et al., 2012): cardiovascular functioning (systolic and diastolic blood pressure), inflammation (C-reactive protein), lipid and general metabolic activity (body mass index, waist and hip circumference, lipid profile, $\mathrm{HbA1C}$ ), and hypothalamic pituitary adrenal (HPA) axis activity ${ }^{2}$ (cortisol, calculated as area under the curve, Pruessner et al., 2003). An individual received a " 1 " per indicator if their value fell into the highest-risk quartile within the present sample (in the case of multiple indicators per system, the mean was used). Scores ranged from 0 to $1(0=$ no biomarker within the system in risk quartile; $1=$ all biomarkers within the system within risk quartile). The allostatic load index was computed as the sum of the four systems with possible scores ranging from 0 to $4(M=1.07, S D=0.87)$.

\section{Relationship Satisfaction}

Relationship satisfaction was assessed by the relationship assessment scale (Hendrick, 1988; Hendrick et al., 1998). Participants rated seven items (e.g., "How well does your partner meet your needs?") from not at all (1) to very much (5); Cronbach's $\alpha=0.89$ and $M=4.17, S D=0.70)$.

\section{Statistical Analyses}

Hierarchical linear 2-level random intercept models for the outcomes (1) goal progress, (2) relationship satisfaction, and (3) allostatic load were conducted using the $\mathrm{R}$ package lme4 (Bates et al., 2014). Predictor variables were (1) the number of joint goals (externally-rated) at the couple-level, (2) overreporting at the individual-level, and (3) the interaction between the two. The interaction was decomposed by calculating simple slopes (Preacher et al., 2006). Gender, age, language of study participation (English vs. Mandarin), and selfrated health ("poor $=1$ " to "excellent $=5$ ") served as

\footnotetext{
1 "No over-reporting" mostly means there was consensus between self-report and external rating. Only in a minority of goals (5.9-11.1\% for each of the three goals), the external rating but not the self-rating was joint.

${ }^{2}$ Thirty couples were not asked to provide saliva samples because of thyroid dysfunction.
} 
TABLE 1 | Descriptive statistics and correlations of sample characteristics $(N=236)$ and study variables.

\begin{tabular}{|c|c|c|c|c|c|c|c|c|c|c|c|c|}
\hline & \multirow[t]{2}{*}{ Variables } & \multicolumn{2}{|c|}{ Women } & \multicolumn{2}{|c|}{ Men } & \multicolumn{7}{|c|}{ Correlations } \\
\hline & & $M$ & (SD) & $M$ & (SD) & 1 & 2 & 3 & 4 & 5 & 6 & 7 \\
\hline 1 & Age & 69.77 & $5.44^{d}$ & 72.26 & $6.22^{d}$ & $0.66 * * *$ & -1.70 & -0.01 & 0.05 & -0.01 & 0.10 & 0.02 \\
\hline 2 & Self-rated health & 3.27 & 0.96 & 3.25 & 0.95 & -1.60 & $0.39^{\star \star \star}$ & 0.06 & -0.12 & $0.41^{\star \star \star}$ & -0.05 & 0.03 \\
\hline 3 & Goal progress ${ }^{a}$ & 3.15 & 0.87 & 3.06 & 0.99 & -0.60 & 0.15 & 0.07 & 0.17 & -0.10 & 0.05 & 0.05 \\
\hline 4 & Allostatic load ${ }^{b}$ & 1.00 & 0.80 & 1.15 & 0.93 & 0.04 & -0.10 & -0.12 & 0.09 & -0.08 & -1.50 & -1.40 \\
\hline 5 & Relationship satisfaction ${ }^{c}$ & 4.06 & $0.80^{d}$ & 4.29 & $0.57^{d}$ & -0.18 & $0.40^{\star \star \star}$ & 0.07 & -0.03 & $0.48^{\star *}$ & 0.10 & 0.03 \\
\hline 6 & Number of joint goals (self-report) & 1.58 & $1.09^{d}$ & 1.97 & $0.98^{d}$ & -0.05 & 0.01 & $0.22^{*}$ & 0.07 & $0.40^{\star \star \star}$ & $0.30^{\star * \star}$ & $0.58^{\star \star \star}$ \\
\hline \multirow[t]{2}{*}{7} & Over-reporting of joint goals & 0.88 & $0.88^{d}$ & 1.19 & $0.95^{d}$ & -0.11 & 0.20 & 0.06 & -0.01 & $0.25^{\star \star}$ & $0.60^{\star \star \star}$ & $0.31^{\star * *}$ \\
\hline & & $N$ & $\%$ & $N$ & $\%$ & & & & & & & \\
\hline \multicolumn{13}{|c|}{ Ethnicity } \\
\hline & Caucasian/White & 71 & 60.2 & 70 & 59.8 & & & & & & & \\
\hline & Asian & 39 & 33.1 & 42 & 35.9 & & & & & & & \\
\hline & Aboriginal & 2 & 1.7 & 0 & 0 & & & & & & & \\
\hline & Hispanic & 1 & 0.8 & 1 & 0.9 & & & & & & & \\
\hline & Other & 5 & 4.2 & 4 & 3.4 & & & & & & & \\
\hline \multicolumn{2}{|c|}{ English language $^{e}$} & 69 & 58.5 & 69 & 58.5 & & & & & & & \\
\hline \multicolumn{2}{|c|}{ University education or equivalent } & 82 & 70.1 & 79 & 66.9 & & & & & & & \\
\hline \multicolumn{2}{|c|}{ Retired } & 106 & 90.6 & 100 & 85.5 & & & & & & & \\
\hline
\end{tabular}

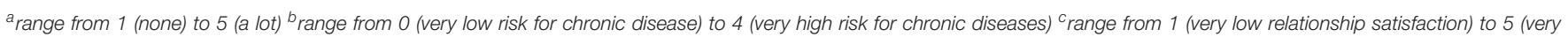

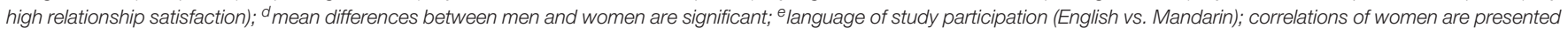

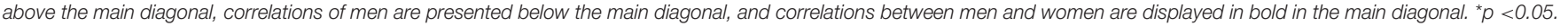
${ }^{\star \star} p<0.01,{ }^{\star \star *} p<0.001$.

TABLE 2 | Domains of goals and the proportion of joint goals.

\begin{tabular}{|c|c|c|c|c|c|c|}
\hline \multirow[t]{2}{*}{ Domain } & \multirow{2}{*}{$\begin{array}{l}\% \text { of goals falling } \\
\text { into this domain }\end{array}$} & \multirow[t]{2}{*}{ Example goals } & \multicolumn{2}{|c|}{$\%$ of joint goals } & \multirow[t]{2}{*}{$x^{2}$} & \multirow[t]{2}{*}{$p$} \\
\hline & & & Within this domain & $\begin{array}{c}\text { Outside } \\
\text { this domain }\end{array}$ & & \\
\hline Health & 54.4 & "do a full health check", "walk at least 15 minutes a day" & 39.5 & 20.7 & 28.915 & $<0.001$ \\
\hline Social & 53.2 & "invite family and friends for dinner" & 31.8 & 29.9 & 0.300 & n.s. \\
\hline Work and finances & 42.0 & "paperwork for taxes" & 22.7 & 38.8 & 15.772 & $<0.001$ \\
\hline Leisure & 39.8 & "taking photos" & 31.8 & 30.4 & 0.162 & n.s. \\
\hline Home management & 25.3 & "clean out closet and pictures" & 30.3 & 31.1 & 0.038 & n.s. \\
\hline Other & 40.8 & & 27.3 & 33.3 & 2.247 & n.s. \\
\hline
\end{tabular}

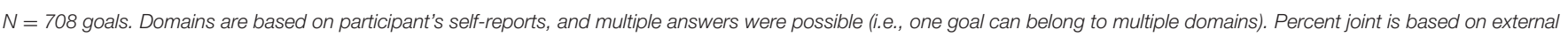

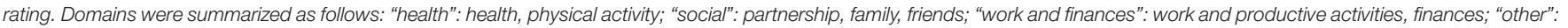
cognition and memory, volunteer, other; n.s., non significant.

${ }^{a}$ All goals, which do NOT belong to this domain.

control variables. All continuous variables were grand-mean centered and $R^{2}$ is reported (see Supplementary Material 1 for analytic details).

\section{RESULTS}

\section{Descriptive Statistics for Joint Goals}

External ratings identified one-third of goals (30.9\%) as joint, with $65.3 \%$ of participants having at least one goal in common with the partner. Self-reports identified two-thirds of goals as joint $(60.1 \%)$, twice as many as the external ratings suggest. Most participants $(85.2 \%)$ self-reported at least one joint goal. Almost one-third (31.4\%) reported wanting to achieve all three goals together with their partner. The difference between self-reports and external ratings was positively biased, and common: $65.6 \%$ of participants over-reported at least one joint goal. Men were older, more satisfied with their relationship, and reported more joint goals than women. No gender differences were found for goal progress and allostatic load (see Table 1).

Most goals were in the health domain (54.4\%), followed by social (53.2\%), work and finances (42.0\%), and leisure $(39.8 \%)$. Health-related goals had the highest proportion of joint goals (39.5\% based on external ratings), whereas work and finance goals had the lowest proportion of joint goals $(22.7 \%$; see Table 2).

Self-reported and externally-rated joint goals were positively correlated $(r=0.29, p<0.001)$. The number of joint goals (self-reported and externally-rated) was not significantly 
TABLE 3 | Multilevel analysis with goal progress, relationship-satisfaction, and allostatic load as outcome variables ( $N=118$ couples).

\begin{tabular}{|c|c|c|c|c|c|c|c|c|c|}
\hline & \multicolumn{3}{|c|}{ Goal progress } & \multicolumn{3}{|c|}{ Allostatic load } & \multicolumn{3}{|c|}{ Relationship satisfaction } \\
\hline & Coefficient (b) & $S E$ & $p$-value & Coefficient (b) & $S E$ & $p$-value & Coefficient (b) & $S E$ & $p$-value \\
\hline Intercept & $3.185^{\star \star \star}$ & 0.215 & $<0.001$ & $1.056^{\star \star \star}$ & 0.161 & $<0.001$ & $4.03^{\star \star \star}$ & 0.085 & $<0.001$ \\
\hline \multicolumn{10}{|l|}{ Level 1 (person) } \\
\hline Over-reporting of joint goals & 0.016 & 0.080 & 0.841 & -0.042 & 0.074 & 0.568 & $0.132^{\star}$ & 0.050 & 0.009 \\
\hline Age (in years) & -0.011 & 0.011 & 0.328 & 0.011 & 0.010 & 0.259 & 0.002 & 0.008 & 0.200 \\
\hline Gender & 0.097 & 0.118 & 0.414 & -0.156 & 0.109 & 0.154 & $-0.181^{\star \star}$ & 0.065 & 0.007 \\
\hline Self-rated health & $0.160^{\star}$ & 0.068 & 0.020 & $-0.131^{\star}$ & 0.063 & 0.040 & $0.168^{\star \star \star}$ & 0.044 & $<0.001$ \\
\hline English language ${ }^{a}$ & $-0.327^{\star}$ & 0.139 & 0.019 & $0.271^{*}$ & 0.129 & 0.040 & $0.370^{\star \star \star}$ & 0.960 & $<0.001$ \\
\hline \multicolumn{10}{|l|}{ Level 2 (couple) } \\
\hline Number of joint goals ${ }^{b}$ & -0.049 & 0.093 & 0.595 & 0.000 & 0.021 & 0.999 & $0.160^{*}$ & 0.085 & 0.016 \\
\hline \multicolumn{10}{|l|}{ Interaction } \\
\hline Over-reporting $x$ number of joint goals & $-0.196^{\star}$ & 0.092 & 0.035 & $0.184^{\star}$ & 0.086 & 0.033 & -0.048 & 0.061 & 0.431 \\
\hline \multicolumn{10}{|l|}{ Additional information } \\
\hline ICC & 0.071 & & & 0.087 & & & 0.480 & & \\
\hline
\end{tabular}

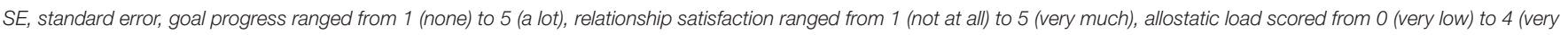

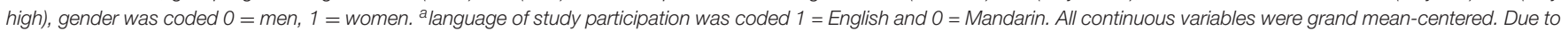

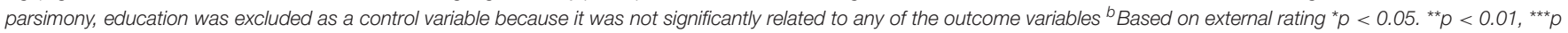
$<0.001$.

correlated with goal progress or allostatic load. Relationship satisfaction was positively associated with self-reported joint goals $(r=0.24, p<0.001)$ and over-reporting $(r=0.15, p$ $=0.02$ ). Intraclass correlations (ICC) ranged from 0.071 (goal progress) over 0.087 for allostatic load to 0.480 (relationship satisfaction), indicating that most of the variance was at the individual level.

\section{Goal Progress (Hp1)}

Results regarding Hp1 concerned a moderation of over-reporting and joint goals on goal progress (Table 3). Control variables showed significant main effects for self-rated health $(b=0.16, S E$ $=0.07, p=0.020)$ and English as language of study participation $(b=-0.33, S E=0.14, p=0.019)$. No main effects emerged for over-reporting or number of joint goals. As hypothesized, the interaction between over-reporting and the number of externallyrated joint goals was significant $(b=-0.20, S E=0.09, p=$ 0.035; see Figure 1). More joint goals were related to more goal progress, but only when over-reporting was low; the simple slope for low over-reporting ( $1 S D$ below the mean) was 0.19 (0.08), $t=2.21, p=0.028$; the simple slope for average over-reporting (mean) was $0.001(0.07), t=0.01, p=0.993$ and the simple slope for high over-reporting ( $1 S D$ above the mean) was -0.19 (0.12), $t=1.49, p=0.138$. The model explained $13.99 \%$ of the variance.

\section{Allostatic Load (Hp2)}

Hp2 was examined using a similar multilevel model (Table 3). There were positive main effects for self-rated health $(b=$ $-0.13, S E=0.06, p=0.040)$ and English as language of study participation $(b=0.27, S E=0.13, p=0.040)$. No main effects for joint goals and over-reporting were found. However, the hypothesized interaction between the number of joint goals and over-reporting was significant $(b=0.18, S E=0.09, p=$ 0.033; Figure 1). Simple slope analysis indicated that a high number of joint goals in combination with low over-reporting was associated with lower allostatic load; the simple slope for low over-reporting ( $1 S D$ below the mean) was $-0.20(0.07), t$ $=-3.05, p=0.003$; the simple slope for average over-reporting (at mean value) was $-0.02(0.07), t=-0.35, p=0.723$ and the simple slope for high over-reporting ( $1 S D$ above the mean) was $0.15(0.12), t=1.28, p=0.201$. The model explained $15.89 \%$ of the variance.

\section{Relationship Satisfaction (Hp3)}

Better self-rated health $(b=0.17, S E=0.04, p<0.001)$, being a man $(b=-0.18, S E=0.07, p=0.007)$, and English as language of study participation $(b=0.37, S E=0.96, p<0.001)$ were associated with higher relationship satisfaction. There was a significant main effect for the number of externally-rated joint goals $(b=0.16, S E=0.09, p=0.016)$, and for over-reporting $(b=0.13, S E=0.05, p=0.009)$, indicating that participants were more satisfied with their relationship if they over-reported and had more externally judged joint goals ${ }^{3}$. The overall model explained $51.91 \%$ of the variance.

\section{DISCUSSION}

This brief report investigated how joint goals are related to goal progress, allostatic load, and relationship satisfaction. Findings indicate that a high proportion of participants' three most salient goals were joint (external rating 30.9\%, self-report 60.1\%). Comparing participants' self-reports with external ratings of joint goals points to systematic and potentially meaningful differences. About two-thirds of participants over-reported at least one joint goal (thinking their goal was joint without the partner

${ }^{3}$ Calculating all main-analyses without the control variables yielded the same result patterns, see Supplementary Material 4. 


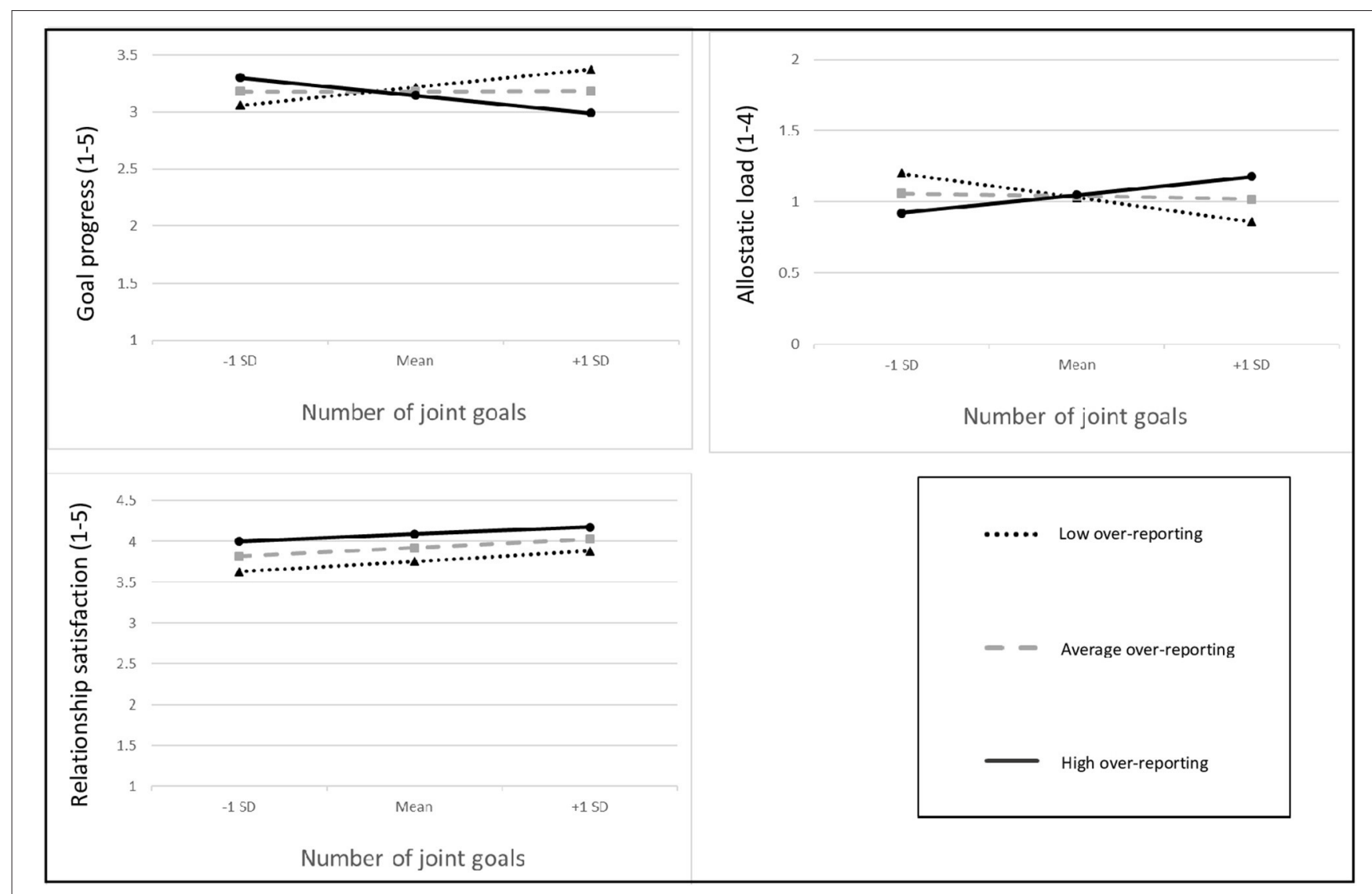

FIGURE 1 | Interactions between the number of joint goals and over-reporting in explaining goal progress (upper left-hand panel), allostatic load (upper right-hand panel), and relationship satisfaction (lower left-hand panel). A larger number of joint goals is related to increased goal progress and lower allostatic load, but only for participants with few over-reporting. In contrast, a higher number of joint goals and more over-reporting are generally linked to higher relationship satisfaction.

mentioning it among their three most salient goals). Results show that the number of externally-rated joint goals in combination with little over-reporting was associated with more goal progress and lower allostatic load. Having many joint goals and overreporting were each related to higher relationship satisfaction.

\section{Joint Goals and Goal Progress (Hp1)}

In line with $\mathrm{Hp1}$, we showed that a high number of joint goals was related to more goal progress 1 week later, but only for participants with low over-reporting. By comparing both partners' goals, we were able to disentangle the effects of joint goal perceptions and over-reporting and uncovered unique associations with goal progress. This finding is consistent with the idea that it is important to know a partner's goals to engage in goal coordination. According to the TransactiveGoal-Dynamics Theory (Fitzsimons and Finkel, 2018), goal coordination is a key factor for translating joint goals into goal progress. Inaccurate perceptions of joint goals could waste energy when trying to get a partner involved in progress on a goal they do not care about. Ultimately, this could lead to frustration and undermine goal-relevant efforts. Possible mechanisms behind the observed moderation of joint goals and over-reporting might be more effective collaborative problem-solving (Hoppmann and Gerstorf, 2013) or higher frequency and enjoyment of collaboration (Schindler et al., 2010).

\section{Allostatic Load (Hp2)}

In line with $\mathrm{Hp} 2$, joint goals were related to better individual health if perceived accurately. We also found that the highest proportion of joint goals appeared in the health and physical activity domains. This is consistent with propositions that health behaviors may be important variables linking psychosocial resources with allostatic load (Wiley et al., 2017). Goal coordination (Fitzsimons and Finkel, 2018), joint implementation of goal-directed activity (Berli et al., 2018), and dyadic planning (Keller et al., 2017) all require knowledge of a partner's goals and have been linked to health behavior engagement. Interpreting the moderation effect, we assume that an accurate perception of the partners' salient goals (little overreporting) facilitates jointly coordinating goal-directed activity. Importantly, no causal conclusions can be drawn from our findings. For example, Wiley et al. (2017) argue that the reverse is possible: high allostatic load could undermine psychosocial resources, for example, by acting as a stressor. 


\section{Relationship Satisfaction (Hp3)}

In line with $\mathrm{Hp} 3$, a larger number of joint goals was associated with higher relationship satisfaction. One possible linking variable could be trait similarity: joint goals are more common in couples with similar traits (Gray and Coons, 2017), and trait similarity among partners, in turn, has been linked with high relationship satisfaction (e.g., Malouff et al., 2010). Notably, the reverse (relationship satisfaction predicting joint goals) could be true as well and needs to be tested using more mechanismoriented longitudinal study designs.

An unexpected result relates to the fact that more overreporting was associated with higher relationship satisfaction. There has been a debate about whether it is necessary to view the world accurately or if it might sometimes be adaptive to have positively biased views. In this sense, over-reporting could be interpreted as an indicator of positive illusions. Seminal work by Taylor and Brown (1994) argues that positive illusions have positive effects on well-being. Our results linking overreporting with relationship satisfaction are consistent with this idea. Importantly, the divergent findings regarding goal progress and allostatic load (in interaction with the number of joint goals) are in line with Taylor's and Brown's (1994) proposition that positive illusions do not have to be unanimously positive and that, in fact, they can backfire. It might be that joint goals and positively biased perceptions capture processes that are essential for satisfying relationships; however, not having an accurate reading of a partner's goals may undermine collaborative efforts to work toward goals and play a role in allostatic load, e.g., through poorer health behaviors (Kaul and Lakey, 2003).

\section{Implications of Findings}

So what shall we tell older adult couples? It depends on what is most important for a given couple in a specific situation: that they make progress on their goals, that they optimize their health, or that they happily live together. This is in line with previous research showing that consensus between couples differs in its effect on distress depending on the area of consensus (Reyes et al., 2020). If being satisfied with their relationship is the priority, biased perceptions might not be so bad (Story et al., 2007).

There is initial evidence that addressing health behavior change in both partners of a couple has favorable outcomes (Jackson et al., 2015; Richards et al., 2018). Our results further underpin the notion that health interventions should capitalize on significant others.

If the importance of joint goals is corroborated in future studies, it will be essential to inform older adults about the meaning of joint goals. It would be interesting for future studies to develop interventions showing partners how they can turn "me goals" into "we goals" and to facilitate translating them into action, for example, through dyadic behavior change techniques (Knoll et al., 2017).

To give a broader outlook, integrating goal setting and progress discussions into patient care plans is an increasing need in medicine (Schulman-Green et al., 2006). The findings of this study suggest that including the patient's partner in the goalsetting process poses a crucial step to be considered in all efforts of improving patient-centered care.

\section{Limitations}

Our goal assessment has some degree of ambiguity. We focused on three spontaneously generated particularly salient goals. It is possible that when one partner reported their goal as joint, but the other partner did not list it, that it could have shown up further down the list. Also, a focus on only three goals restricts variability. However, as goals represent a very complex system and people often pursue multiple personal goals across various life domains which might compete with each other (Kruglanski et al., 2002; Riediger and Freund, 2004; Presseau et al., 2013), a "complete list of their individual and joint goals" can probably never be reached. Nevertheless, focusing on particularly salient goals should be seen as a starting point that warrants further extension. In addition, we do not distinguish between partners sharing a goal and wanting to achieve it together. However, with this qualitative assessment of goals, we were able to assess and rate individually generated personal goals without imposing restrictions on their content.

Of note, the effects of joint goals and over-reporting could be different in younger adults, recently married older adults and adults living with health problems. For example, as goal pursuit might be particularly difficult for adults living with significant health problems, this population might especially benefit from joint goals and collaborative problem solving (Schindler et al., 2010).

Furthermore, data analytic choices were made conceptually and had to consider power limitations related to the sample size (118 couples). We hope that future work with larger samples builds on our findings and extends them by estimating actor and partner effects using SEM approaches.

Lastly, we cannot draw conclusions about the underlying mechanisms. Recent research on dyadic self-regulatory processes such as dyadic planning (Knoll et al., 2017), couple self-efficacy, and communal coping (Lewis et al., 2006) might be starting points. Finally, no causal conclusions can be drawn based on our correlational findings. To address these limitations, a follow-up study assessing goals more comprehensively and experimentally manipulating potential underlying factors by teaching different dyadic goal setting and behavior change strategies would be valuable.

In conclusion, when studying older adults' goals, it is essential to include the partner because our results show that older adults want to achieve a high proportion of their goals together as a team. A high number of joint goals appears to have positive ramifications for diverse outcomes such as goal progress, allostatic load, and relationship satisfaction.

\section{DATA AVAILABILITY STATEMENT}

The raw data supporting the conclusions of this article will be made available by the authors, without undue reservation.

\section{ETHICS STATEMENT}

The studies involving human participants were reviewed and approved by Clinical Research Ethics Board of the 
University of British Columbia. The patients/participants provided their written informed consent to participate in this study.

\section{AUTHOR CONTRIBUTIONS}

$\mathrm{CH}, \mathrm{MA}, \mathrm{DG}$, and $\mathrm{KM}$ designed and directed the project and supervised the work. NU performed the data analysis and the goal rating and wrote the manuscript. VM managed the project, recruited participants, performed the study, and did the data management. SB performed the goal rating and assisted with drafting the manuscript. TP contributed to the data analysis and discussing the results. All authors commented on the manuscript and contributed to the final version of the manuscript.

\section{REFERENCES}

Avivi, Y. E., Laurenceau, J.-P., and Carver, C. S. (2009). Linking relationship quality to perceived mutuality of relationship goals and perceived goal progress. J. Soc. Clin. Psychol. 28, 137-164. doi: 10.1521/jscp.2009.28.2.137

Baltes, M. M., and Carstensen, L. L. (1999). "Social-psychological theories and their applications to aging: from individual to collective," in Handbook of Theories of Aging, eds V. L. Bengtson and K. W. Schaie (New York, NY, US: Springer Publishing Co), 209-226.

Bates, D., Mächler, M., Bolker, B., and Walker, S. (2014). Fitting linear mixedeffects models using lme4. J. Stat. Softw. 67:1. doi: 10.18637/jss.v067.i01

Berg, C. A., and Upchurch, R. (2007). A developmental-contextual model of couples coping with chronic illness across the adult life span. Psychol. Bull. 133, 920-954. doi: 10.1037/0033-2909.133.6.920

Berli, C., Bolger, N., Shrout, P. E., Stadler, G., and Scholz, U. (2018). Interpersonal processes of couples' daily support for goal pursuit: the example of physical activity. Person. Soc. Psychol. Bull. 44, 332-344. doi: 10.1177/0146167217739264

Brooks, K. P., Gruenewald, T., Karlamangla, A., Hu, P., Koretz, B., and Seeman, T. E. (2014). Social relationships and allostatic load in the MIDUS study. Health Psychol. 33, 1373-1381. doi: 10.1037/a0034528

Carstensen, L. L., Fung, H. H., and Charles, S. T. (2003). Socioemotional Selectivity Theory and the regulation of emotion in the second half of life. Motiv. Emot. 27, 103-123. doi: 10.1023/A:1024569803230

Chen, E., Miller, G. E., Lachman, M. E., Gruenewald, T. L., and Seeman, T. E. (2012). Protective factors for adults from low childhood socioeconomic circumstances: the benefits of shift-and-persist for allostatic load. Psychosom. Med. 74, 178-186. doi: 10.1097/PSY.0b013e31824206fd

English, T., and Carstensen, L. L. (2014). Selective narrowing of social networks across adulthood is associated with improved emotional experience in daily life. Int. J. Behav. Dev. 38, 195-202. doi: 10.1177/0165025413515404

Feeney, B. C., and Collins, N. L. (2015). A new look at social support: a theoretical perspective on thriving through relationships. Person. Soc. Psychol. Rev. 19, 113-147. doi: 10.1177/1088868314544222

Fitzsimons, G. M., and Finkel, E. J. (2018). Transactive-goal-dynamics theory: a discipline-wide perspective. Curr. Dir. Psychol. Sci. 27, 332-338. doi: $10.1177 / 0963721417754199$

Fowers, B. J., and Owenz, M. B. (2010). A Eudaimonic theory of marital quality. J. Family Theory Rev. 2, 334-352. doi: 10.1111/j.1756-2589.2010.00065.x

Gagné, F. M., and Lydon, J. E. (2004). Bias and accuracy in close relationships: an integrative review. Person. Soc. Psychol. Rev. 8, 322-338. doi: 10.1207/s15327957pspr0804_1

Gray, J. S., and Coons, J. V. (2017). Trait and goal similarity and discrepancy in romantic couples. Pers. Individ. Dif. 107, 1-5. doi: 10.1016/j.paid.2016.11.024

Hendrick, S. S. (1988). A generic measure of relationship satisfaction. J. Marr. Family 50, 93-98. doi: 10.2307/352430

\section{FUNDING}

This work was supported by a grant from the Canadian Institutes of Health Research (MOP-123501 to $\mathrm{CH}$, MA, and DG). NU gratefully acknowledges funding from the German Research Foundation (UN 405/1; no. 396651852). CH gratefully acknowledges the support of the Canada Research Chairs Program. VM gratefully acknowledges support from the Social Sciences and Humanities Research Council. MA acknowledges support from the Canada Research Chairs Program.

\section{SUPPLEMENTARY MATERIAL}

The Supplementary Material for this article can be found online at: https://www.frontiersin.org/articles/10.3389/fpsyg. 2021.623037/full\#supplementary-material

Hendrick, S. S., Dicke, A., and Hendrick, C. (1998). The relationship assessment scale. J. Soc. Pers. Relat. 15, 137-142. doi: 10.1177/0265407598151009

Hooker, K. (2002). New directions for research in personality and aging: comprehensive model for linking levels, structures, and processes. J. Res. Pers. 36, 318-334. doi: 10.1016/S0092-6566(02)00012-0

Hoppmann, C. A., and Gerstorf, D. (2013). Spousal goals, affect quality, and collaborative problem solving: evidence from a time-sampling study with older couples. Res. Hum. Dev. 10, 70-87. doi: 10.1080/15427609.2013.760260

Hoppmann, C. A., and Gerstorf, D. (2014). Biobehavioral pathways underlying spousal health dynamics: its nature, correlates, and consequences. Gerontology 60, 458-465. doi: 10.1159/000357671

Hoppmann, C. A., and Klumb, P. L. (2006). Daily goal pursuits predict cortisol secretion and mood states in employed parents with preschool children. Psychosom. Med.68, 887-894. doi: 10.1097/01.psy.0000238232.46870.f1

Jackson, S. E., Steptoe, A., and Wardle, J. (2015). The influence of partner's behavior on health behavior change: the English longitudinal study of ageing. JAMA Intern. Med. 175, 385-392. doi: 10.1001/jamainternmed.2014.7554

Juster, R.-P., McEwen, B. S., and Lupien, S. J. (2010). Allostatic load biomarkers of chronic stress and impact on health and cognition. Neurosci. Biobehav. Rev. 35, 2-16. doi: 10.1016/j.neubiorev.2009.10.002

Kaul, M., and Lakey, B. (2003). Where is the support in perceived support? The role of generic relationship satisfaction and enacted support in perceived support's relation to low distress. J. Soc. Clin. Psychol. 22, 59-78. doi: $10.1521 /$ jscp.22.1.59.22761

Keller, J., Fleig, L., Hohl, D. H., Wiedemann, A. U., Burkert, S., Luszczynska, A., et al. (2017). Which characteristics of planning matter? Individual and dyadic physical activity plans and their effects on plan enactment. Soc. Sci. Med. 189, 53-62. doi: 10.1016/j.socscimed.2017.07.025

Kiecolt-Glaser, J. K., and Wilson, S. J. (2017). Lovesick: how couples' relationships influence health. Annu. Rev. Clin. Psychol. 13, 421-443. doi: 10.1146/annurev-clinpsy-032816-045111

Knoll, N., Hohl, D. H., Keller, J., Schuez, N., Luszczynska, A., and Burkert, S. (2017). Effects of dyadic planning on physical activity in couples: a randomized controlled trial. Health Psychol. 36, 8-20. doi: 10.1037/hea0000423

Kruglanski, A. W., Shah, J. Y., Fishbach, A., Friedman, R., Chun, W. Y., and SleethKeppler, D. (2002). "A theory of goal systems," in Advances in Experimental Social Psychology, ed M. P. Zanna (San Diego, CA: Academic Press), 331-378. doi: 10.1016/S0065-2601(02)80008-9

Lauer, R. H., Lauer, J. C., and Kerr, S. T. (1990). The long-term marriage: perceptions of stability and satisfaction. Int. J. Aging Human Dev. 31, 189-195. doi: 10.2190/H4X7-9DVX-W2N1-D3BF

Lewis, M. A., McBride, C. M., Pollak, K. I., Puleo, E., Butterfield, R. M., and Emmons, K. M. (2006). Understanding health behavior change among couples: an interdependence and communal coping approach. Soc. Sci. Med. 62, 1369-1380. doi: 10.1016/j.socscimed.2005.08.006 
Malouff, J. M., Thorsteinsson, E. B., Schutte, N. S., Bhullar, N., and Rooke, S. E. (2010). The Five-Factor Model of personality and relationship satisfaction of intimate partners: a meta-analysis. J. Res. Pers. 44, 124-127. doi: 10.1016/j.jrp.2009.09.004

Mann, T., De Ridder, D., and Fujita, K. (2013). Self-regulation of health behavior: social psychological approaches to goal setting and goal striving. Health Psychol. 32, 487-498. doi: 10.1037/a0028533

Martz, J. M., Verette, J., Arriaga, X. B., Slovik, L. F., Cox, C. L., and Rusbult, C. E. (1998). Positive illusion in close relationships. Pers. Relatsh. 5, 159-181. doi: 10.1111/j.1475-6811.1998.tb00165.x

Meegan, S. P., and Berg, C. A. (2002). Contexts, functions, forms, and processes of collaborative everyday problem solving in older adulthood. Int. J. Behav. Dev. 26, 6-15. doi: 10.1080/01650250143000283

Meegan, S. P., and Goedereis, E. A. (2006). Life task appraisals, spouse involvement in strategies, and daily affect among short-and long-term married couples. J. Family Psychol. 20:319. doi: 10.1037/0893-3200.20.2.319

Pauly, T., Michalowski, V. I., Nater, U. M., Gerstorf, D., Ashe, M. C., Madden, K. M., et al. (2019). Everyday associations between older adults' physical activity, negative affect, and cortisol. Health Psychol. 38, 494-501. doi: $10.1037 /$ hea0000743

Preacher, K. J., Curran, P. J., and Bauer, D. J. (2006). Computational tools for probing interactions in multiple linear regression, multilevel modeling, and latent curve analysis. J. Educ. Behav. Stat. 31, 437-448. doi: 10.3102/10769986031004437

Presseau, J., Tait, R. I., Johnston, D. W., Francis, J. J., and Sniehotta, F. F. (2013). Goal conflict and goal facilitation as predictors of daily accelerometerassessed physical activity. Health Psychol. 32, 1179-1187. doi: 10.1037/a00 29430

Priest, J. B., Woods, S. B., Maier, C. A., Parker, E. O., Benoit, J. A., and Roush, T. R. (2015). The biobehavioral family model: close relationships and allostatic load. Soc. Sci. Med. 142, 232-240. doi: 10.1016/j.socscimed.2015.08.026

Pruessner, J. C., Kirschbaum, C., Meinlschmid, G., and Hellhammer, D. H. (2003). Two formulas for computation of the area under the curve represent measures of total hormone concentration versus time-dependent change. Psychoneuroendocrinology 28, 916-931. doi: 10.1016/S0306-4530(02) 00108-7

Reyes, L. M., Lenger, K. A., Rauer, A., Roberson, P. N., Cordova, J. V., Gray, T., et al. (2020). Consensus and relationship distress before and after a brief couples' intervention. J. Family Psychol. 34:128. doi: 10.1037/fam00 00577

Richards, E. A., Franks, M. M., McDonough, M. H., and Porter, K. (2018). 'Let's move:' a systematic review of spouse-involved interventions to promote physical activity. Int. J. Health Promot. Educ. 56, 51-67. doi: $10.1080 / 14635240.2017 .1415160$
Riediger, M., and Freund, A. M. (2004). Interference and facilitation among personal goals: differential associations with subjective well-being and persistent goal pursuit. Person. Soc. Psychol. Bull. 30, 1511-1523. doi: 10.1177/0146167204271184

Schindler, I., Berg, C. A., Butler, J. M., Fortenberry, K. T., and Wiebe, D. J. (2010). Late-midlife and older couples' shared possible selves and psychological well-being during times of illness: the role of collaborative problem solving. J. Gerontol. B 65B, 416-424. doi: 10.1093/geronb/gbq030

Schulman-Green, D. J., Naik, A. D., Bradley, E. H., McCorkle, R., and Bogardus, S. T. (2006). Goal setting as a shared decision making strategy among clinicians and their older patients. Patient Educ. Couns. 63, 145-151. doi: 10.1016/j.pec.2005.09.010

Seeman, T. E., Crimmins, E., Huang, M.-H., Singer, B., Bucur, A., Gruenewald, T., et al. (2004). Cumulative biological risk and socio-economic differences in mortality: MacArthur studies of successful aging. Soc. Sci. Med. 58, 1985-1997. doi: 10.1016/S0277-9536(03)00402-7

Seeman, T. E., and Gruenewald, T. L. (2006). “Allostasis and allostatic load over the life course," in Medical and Psychiatric Comorbidity Over the Course of Life, ed William W. Eaton (Washington, DC: American Psychiatric Pub), 179-196.

Seeman, T. E., Singer, B. H., Ryff, C. D., Love, G. D., and Levy-Storms, L. (2002). Social relationships, gender, and allostatic load across two age cohorts. Psychosom. Med. 64, 395-406. doi: 10.1097/00006842-200205000-00004

Story, T. N., Berg, C. A., Smith, T. W., Beveridge, R., Henry, N. J., and Pearce, G. (2007). Age, marital satisfaction, and optimism as predictors of positive sentiment override in middle-aged and older married couples. Psychol. Aging 22:719. doi: 10.1037/0882-7974.22.4.719

Taylor, S. E., and Brown, J. D. (1994). Positive illusions and well-being revisited: separating fact from fiction. Psychol. Bull. 116, 21-27. doi: 10.1037/0033-2909.116.1.21

Wiley, J. F., Bei, B., Bower, J. E., and Stanton, A. L. (2017). Relationship of psychosocial resources with allostatic load: a systematic review. Psychosom. Med. 79, 283-292. doi: 10.1097/PSY.0000000000000395

Conflict of Interest: The authors declare that the research was conducted in the absence of any commercial or financial relationships that could be construed as a potential conflict of interest.

Copyright (C) 2021 Ungar, Michalowski, Baehring, Pauly, Gerstorf, Ashe, Madden and Hoppmann. This is an open-access article distributed under the terms of the Creative Commons Attribution License (CC BY). The use, distribution or reproduction in other forums is permitted, provided the original author(s) and the copyright owner(s) are credited and that the original publication in this journal is cited, in accordance with accepted academic practice. No use, distribution or reproduction is permitted which does not comply with these terms. 